Equatorial Kelvin waves as revealed by EOS Microwave Limb Sounder observations and European Centre for Medium-Range Weather Forecasts analyses: Evidence for slow Kelvin waves of zonal wave number 3

Article

Feng, L., Harwood, R., Brugge, R., O'Neill, A., Froidevaux, L., Schwartz, M. and Waters, J. (2007) Equatorial Kelvin waves as revealed by EOS Microwave Limb Sounder observations and European Centre for Medium-Range Weather Forecasts analyses: Evidence for slow Kelvin waves of zonal wave number 3. Journal of Geophysical Research - Atmospheres, 112 (D16). D16106. ISSN 0148-0227 doi:

https://doi.org/10.1029/2006JD008329 Available at https://centaur.reading.ac.uk/862/

It is advisable to refer to the publisher's version if you intend to cite from the work. See Guidance on citing.

Published version at: http://dx.doi.org/10.1029/2006JD008329

To link to this article DOI: http://dx.doi.org/10.1029/2006JD008329

Publisher: American Geophysical Union 
All outputs in CentAUR are protected by Intellectual Property Rights law, including copyright law. Copyright and IPR is retained by the creators or other copyright holders. Terms and conditions for use of this material are defined in the End User Agreement.

\section{www.reading.ac.uk/centaur}

\section{CentAUR}

Central Archive at the University of Reading

Reading's research outputs online 


\title{
Equatorial Kelvin waves as revealed by EOS Microwave Limb Sounder observations and European Centre for Medium-Range Weather Forecasts analyses: Evidence for slow Kelvin waves of zonal wave number 3
}

\author{
Liang Feng, ${ }^{1}$ R. S. Harwood, ${ }^{1}$ R. Brugge, ${ }^{2}$ A. O’Neill, ${ }^{2}$ L. Froidevaux, ${ }^{3}$ \\ M. Schwartz, ${ }^{3}$ and J. W. Waters ${ }^{3}$
}

Received 11 December 2006; revised 15 May 2007; accepted 20 May 2007; published 22 August 2007.

[1] Temperature and ozone observations from the Microwave Limb Sounder (MLS) on the EOS Aura satellite are used to study equatorial wave activity in the autumn of 2005. In contrast to previous observations for the same season in other years, the temperature anomalies in the middle and lower tropical stratosphere are found to be characterized by a strong wave-like eastward progression with zonal wave number equal to 3 . Extended empirical orthogonal function (EOF) analysis reveals that the wave 3 components detected in the temperature anomalies correspond to a slow Kelvin wave with a period of 8 days and a phase speed of $19 \mathrm{~m} / \mathrm{s}$. Fluctuations associated with this Kelvin wave mode are also apparent in ozone profiles. Moreover, as expected by linear theory, the ozone fluctuations observed in the lower stratosphere are in phase with the temperature perturbations, and peak around $20-30 \mathrm{hPa}$ where the mean ozone mixing ratios have the steepest vertical gradient. A search for other Kelvin wave modes has also been made using both the MLS observations and the analyses from one experiment where MLS ozone profiles are assimilated into the European Centre for Medium-Range Weather Forecasts (ECMWF) data assimilation system via a 6-hourly 3D var scheme. Our results show that the characteristics of the wave activity detected in the ECMWF temperature and ozone analyses are in good agreement with MLS data.

\begin{abstract}
Citation: Feng, L., R. S. Harwood, R. Brugge, A. O’Neill, L. Froidevaux, M. Schwartz, and J. W. Waters (2007), Equatorial Kelvin waves as revealed by EOS Microwave Limb Sounder observations and European Centre for Medium-Range Weather Forecasts analyses: Evidence for slow Kelvin waves of zonal wave number 3, J. Geophys. Res., 112, D16106, doi:10.1029/2006JD008329.
\end{abstract}

\section{Introduction}

[2] Equatorial Kelvin waves are special types of gravity waves, which propagate both vertically and zonally in the eastward direction, while being meridionally confined within about $15^{\circ}$ of the equator. They are primarily excited by heating due to tropical deep convention [e.g., Holton, 1973; Salby and Garcia, 1987], and play an important role in troposphere-stratosphere exchange by carrying eastward momentum into the stratosphere from the troposphere and transporting stratospheric ozone into the troposphere [Fujiwara and Takahashi, 2001]. Kelvin waves have substantial effects on the global circulation, and can modify the

\footnotetext{
${ }^{1}$ Institute of Atmospheric and Environmental Science, University of Edinburgh, Edinburgh, UK.

${ }^{2}$ Data Assimilation Research Centre, University of Reading, Reading, UK.

${ }^{3}$ Jet Propulsion Laboratory, California Institute of Technology, Pasadena, California, USA.
}

Copyright 2007 by the American Geophysical Union. 0148-0227/07/2006JD008329 thermal structure of the tropical tropopause $[$ Boehm and Verlinde, 2000]. Recent studies [e.g., Canziani and Holton, 1998] also suggest that Kelvin waves are important in driving the westerly phase of the quasi-biennial oscillations (QBOs) observed in zonal winds.

[3] Fast and slow Kelvin wave modes [Canziani and Holton, 1998] have been identified at different altitudes from ground-based [e.g., Shimizu and Tsuda, 1997] as well as satellite-borne observations on meteorological fields. For example, fast Kelvin waves with periods as short as 3 days have been found in the upper stratospheric temperatures from the Limb Infrared Monitoring of the Stratosphere (LIMS) experiments [Salby et al., 1984]. From the Microwave Limb Sounder (MLS) on the Upper Atmosphere Research Satellite (UARS), Mote et al. [2002] identified 4 wave modes in the middle and lower stratosphere, which fall near the boundary between the slow and fast Kelvin waves. Recently, from the GPS radio occultation measurements, Randel and $W u$ [2005] observed slow Kelvin waves of zonal wave number 1 propagating from the tropopause into the lower stratosphere with periods of about 20 days. Moreover, the existing observations suggest the dominance 
(a)MLS Temperature

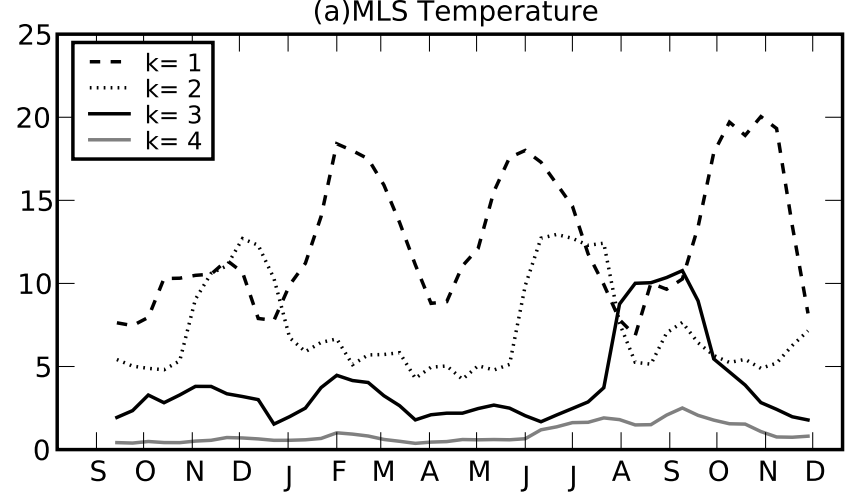

(b)MLS Ozone

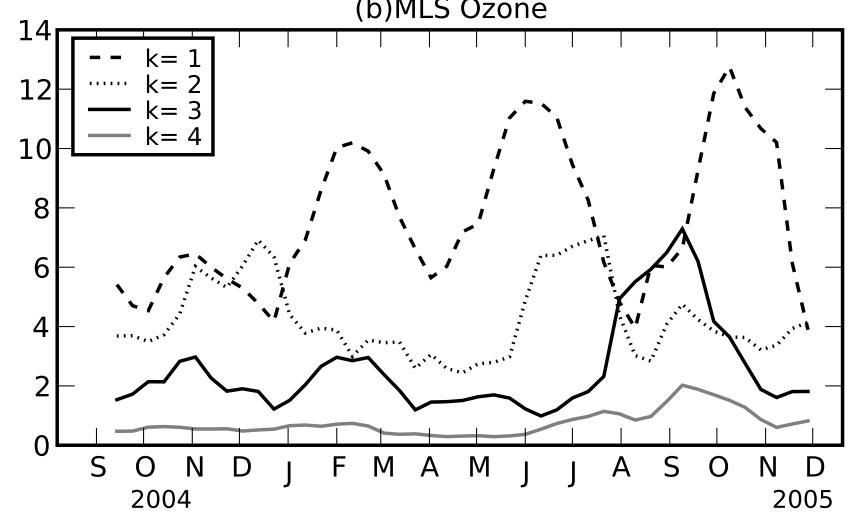

Figure 1. Time evolution of the Lomb periodogram values for the eastward waves of zonal wave number $k=1$ to 4 , detected in (a) MLS temperature and (b) MLS ozone anomalies in the lower stratosphere between $10^{\circ} \mathrm{S}$ and $10^{\circ} \mathrm{N}$. Here, the periodogram values are calculated for a series of overlaid 60-day periods during August 2004 to November 2005 and displayed as a function of the middle day of each 60-day period. Note that averaging has been made over 4 pressure levels (i.e., 46.4, 31.6, 21.5 and $10 \mathrm{hPa}$ ) and 6 separate frequencies between 0.05 to $0.2 \mathrm{cpd}$ (i.e., periods from 5 to 20 days).

of low zonal wave numbers $(<3)$ in the stratospheric Kelvin waves, and particularly, in those observed in the lower stratosphere, although signatures for fast Kelvin waves of zonal wave number 3 have been found in the middle and upper stratosphere [e.g., Hitchman and Leovy, 1988].

[4] Kelvin waves also induce fluctuations in the atmospheric constituents through advection or by changing the temperature-dependent chemical processes. Several investigations have been made to establish the relation between variations in ozone and temperature associated with wave activity [see, e.g., Randel, 1990; Randel and Gille, 1991]. While Timmermans et al. [2005a, 2005b] found a clear in-phase relation between the observed ozone fluctuations from the Global Ozone Monitoring Experiment (GOME) and the temperature perturbations in the European Centre for Medium-Range Weather Forecasts (ECMWF) ERA-40 reanalysis, less conclusive results were obtained for UARS MLS temperature and ozone observations [Mote and Dunkerton, 2004].
[5] The present study extends previous work by using temperature and ozone observations from the Microwave Limb Sounder on the EOS Aura satellite, which was launched in 2004 [Waters et al., 2006]. Here, we focus on a 60-day period from 15 August to 13 October 2005, since during this period, as shown in Figure 1 for the time evolution of the averaged Lomb periodogram values [e.g., Timmermans et al., 2005b] for the eastward waves detected in the EOS MLS temperature and ozone observations, there is a dramatic increase in the wave power of zonal wave number 3 in the lower tropical stratosphere. Such an unusual power surge is interesting, considering that the stratospheric Kelvin waves can be used to diagnose deep convection, and that evidence from the ECMWF reanalysis ERA-15 suggests that Kelvin waves with zonal wave number larger than 2 have important contributions to the wave activity in that vertical range [Tindall et al., 2006]. However, to our knowledge, no previous observation reveals clear and consistent signatures for strong Kelvin waves of zonal wave number 3 in the lower tropical stratosphere.

[6] To some extent, the successful detection of Kelvin waves of zonal wave number 3 reflects the characteristics of EOS MLS temperature and ozone observations: good precision, high vertical resolution and relatively dense spatial and temporal coverage with nearly 1000 profiles daily available between $25^{\circ} \mathrm{S}$ and $25^{\circ} \mathrm{N}$. Similarly, inspection of the corresponding signatures in the meteorological analyses generated by various weather centers helps to evaluate their data assimilation systems. The data sets from the ECMWF reanalysis (ERA-15 and ERA-40) have been shown to be useful in studying Kelvin waves [Straub and Kiladis, 2002; Timmermans et al., 2005b]. The features of the Kelvin waves detected in the UK Met Office (UKMO) temperature and wind analyses [Swinbank and O'Neill, 1994] were also found to be in reasonable agreement with UARS MLS [Amodei et al., 2001]. However, Mote et al. [2002] noted the absence of the signatures in the National Center for Environment Prediction (NCEP) reanalysis for some Kelvin waves observed in UARS MLS temperature profiles. In fact, for most data assimilation systems, deep convection is underresolved in the adopted general circulation model (GCM), while the assimilated information on the stratospheric temperature mainly comes from radiance measurements by nadir instruments with poor vertical resolution. So, the accuracy of their description of the stratospheric Kelvin waves needs detailed evaluation. Here, we are particularly interested in the dynamic consistency of the fluctuations in the analyzed tropical stratospheric ozone field with the temperature perturbations, considering the deficiencies in modeling tropical tracer transport [e.g., Schoeberl et al., 2003].

[7] The present paper is mainly devoted to the Kelvin waves of zonal wave number 3 detected during the autumn of 2005 in both the EOS MLS observations and the analyses from one experiment where EOS MLS ozone profiles are added to the ECMWF data assimilation system of version CY28R1. Section 2 is a brief description of these data sets. In section 3, analysis based on extended empirical orthogonal functions is used to identify Kelvin wave modes of zonal wave number 3 from variations in MLS temperature and ozone observations. In section 4, examination of the 
ECMWF temperature and ozone analyses reveals the same Kelvin wave mode of zonal wave number 3. Finally, a summary is given in section 5 .

\section{Data}

\subsection{EOS MLS Version 1.51 Temperature and Ozone Profiles}

[8] EOS MLS is designed to provide near-global continuous measurements of temperature and geopotential height, as well as a rich set of chemically important trace constituents, including $\mathrm{H}_{2} \mathrm{O}, \mathrm{O}_{3}, \mathrm{~N}_{2} \mathrm{O}, \mathrm{HNO}_{3}, \mathrm{HCl}$, and $\mathrm{ClO}$, in the stratosphere and upper troposphere. Daily, it performs about 3500 vertical scans from the Earth surface to about $90 \mathrm{~km}$, covering from $82^{\circ} \mathrm{S}$ to $82^{\circ} \mathrm{N}$. The MLS temperature and ozone retrievals of version 1.51 are used in this study. The early validation of this data set is described by Froidevaux et al. [2006].

[9] MLS temperature observations are considered to be useful in the vertical range between $0.001 \mathrm{hPa}$ and $316 \mathrm{hPa}$. Like other standard MLS products, the temperature retrievals of version 1.51 are given at a vertical grid of fixed pressure levels, which has 6 levels per factor of 10 in pressure (i.e., 316, 215, 147, 100, 68.1, $46.4 \mathrm{hPa}$, and so on) between 1000 and $0.1 \mathrm{hPa}$. However, their vertical resolution (width of the averaging kernel) is estimated to be about $4 \mathrm{~km}$ in the middle stratosphere, degrading to about $6 \mathrm{~km}$ at $1 \mathrm{hPa}$ and $100 \mathrm{hPa}$. Globally, MLS temperature data are in reasonable agreement with coincident satellite observations with $0-3 \mathrm{~K}$ positive bias in the middle and upper stratosphere. (Early indications are that in the forthcoming version 2.2 of the data this will be replaced by a small negative bias of perhaps $2 \mathrm{~K}$.)

[10] In version 1.51, the standard ozone product is taken from radiometer $\mathrm{R} 3: 240 \mathrm{GHz}$ [Froidevaux et al., 2006], and is considered to be useful in the vertical range between 0.46 and $215 \mathrm{hPa}$, although there is clearly useful ozone information into the upper mesosphere. Early validation shows that MLS ozone data are in good agreement with SAGE II (the Stratospheric Aerosol and Gas Experiment II) and HALOE (the Halogen Occultation Experiment) ozone observations: over the whole pressure range between 1 and $100 \mathrm{hPa}$, the agreement with HALOE is about $5 \%$. The vertical resolution of the retrieved MLS ozone profiles is about $2.7 \mathrm{~km}$ over the pressure range 0.2 to $147 \mathrm{hPa}$, degrading to about $4 \mathrm{~km}$ at $215 \mathrm{hPa}$.

[11] In this study, the daily MLS observations between $10^{\circ} \mathrm{S}$ and $10^{\circ} \mathrm{N}$ are averaged into longitude bins of width $18^{\circ}$. Normally, each bin contains more than 10 temperature and ozone profiles, helping to reduce random observation errors. Our tests show that using higher longitudinal resolution does not affect our results for zonal wave number 1 to 3 significantly. Alternatively, MLS data can be mapped along the equator by using various synoptic mapping techniques [Salby, 1982; Elson and Froidevaux, 1993]. Here, we are interested in a phenomenon with timescale longer than 3 days and without diurnal dependence. Hence a more straightforward approach is adopted. In addition, a band-pass filter has been introduced to remove components with period longer than 45 days or shorter than 3 days from the gridded ozone and temperature data.

\subsection{Experimental Assimilation of MLS Ozone Profiles}

[12] The operational ozone observations from nadir instruments such as the Solar Backscattering Ultraviolet (SBUV/2) [Bhartia et al., 1996] have long been assimilated into the ECMWF data assimilation system [Dethof and Hólm, 2004]. However, their poor vertical resolution may lead to severe underestimation of the tropical zone peak [Dethof, 2003]. Hence this study examines one experimental data set where EOS MLS ozone profiles are added to the ECMWF data assimilation system via a 3D-Var scheme (R. Brugge et al., 3D-var assimilation of ozone profiles from the Microwave Limb Sounder on the Aura satellite, manuscript in preparation, 2007, hereinafter referred to as Brugge et al., manuscript in preparation, 2007).

[13] The MLS ozone assimilation experiment is based on the ECMWF data assimilation system of version CY28R1, where the ozone mass mixing ratio is fully integrated as an additional variable. In the ECMWF system, the temporal evolution of the ozone mass mixing ratio is governed by the tracer transport driven by winds as well as the chemical sink/generation represented by a parameterized relaxation toward chemical equilibrium [Dethof and Hólm, 2004]. Besides MLS ozone profiles, operational ozone observations, such as the total ozone columns of SCIAMACHY on the Envisat [Eskes et al., 2005] and the partial ozone columns of SBUV/2 on the NOAA 16 satellite, have also been assimilated into the experimental system. Comparisons with the control run without MLS ozone observations indicate that assimilation of MLS ozone profiles significantly improves the agreement of the analyzed ozone fields with independent (not assimilated) ozone observations (Brugge et al., manuscript in preparation, 2007). For example, in the tropical lower stratosphere, when MLS ozone profiles are assimilated, the root-mean-square difference between ozone analyses and the coincident ozonesonde measurements is about 10 to $20 \%$, compared to $15-40 \%$ for the control run without MLS data.

[14] For simplicity, the present experiment uses ozone climatology in the radiation calculations of the forecast model used. Hence assimilating MLS ozone profiles has little impact on temperature analyses, which are mainly bound by the assimilation of radiance measurements from nadir instruments such as AMSU (the Advanced Microwave Sounding Unit) and AIRS (the Atmospheric InfraRed Sounder). In fact, just as expected, with a comprehensive set of operational observations of various meteorological fields being also assimilated into the experimental system, the resulting temperature and wind analyses are in good agreement with the operational ECMWF data sets. A more detailed description of the ozone assimilation experiment is given by Brugge et al. (manuscript in preparation, 2007).

[15] The model resolution of the experimental system is chosen to be T159L60, and the analysis time step is 6 hours. In other words, at 0000, 0600, 1200, and 1800 UTC of each experiment day, the temperature, ozone and wind analyses are generated at 60 model vertical levels from the earth surface to $0.1 \mathrm{hPa}$ along a horizontal grid spacing about $120 \mathrm{~km}$. For comparison, the temperature and ozone analyses at each experiment day are interpolated to the MLS pressure levels, before being averaged into the same latitudelongitude bins used in gridding MLS observations. In the 


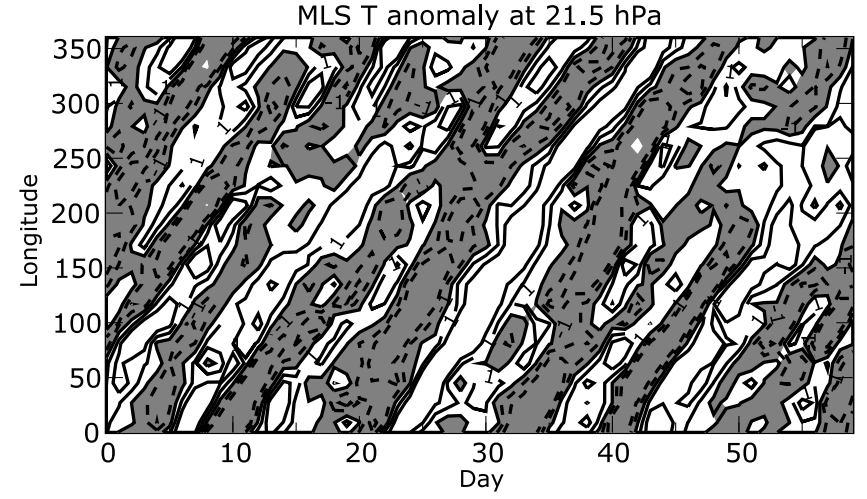

Figure 2. Time-longitude section of MLS temperature anomalies at $21.5 \mathrm{hPa}$ for a 60 -day period since 15 August 2005. The contour interval is $1.0 \mathrm{~K}$ with negative values shaded.

following sections, the resulting data sets are referred to as the ECMWF analyses.

\section{Signatures for Kelvin Waves in MLS Observations}

\subsection{Anomalies in MLS Temperature and Ozone Observations}

[16] We start by investigating wave-like anomalies detected in the MLS temperature and ozone observations during a 60-day period from 15 August to 13 October 2005. Figure 2 is the time-longitude section (Hovmöller diagram) of the deviations from the mean MLS temperature on the $21.5 \mathrm{hPa}$ surface, presenting clear evidence for eastward progression of temperature anomalies at somewhat mixed frequencies and zonal scales. For example, around day 10 (since 15 August 2005), the contribution of the zonal wave 3 to the observed temperature perturbations is quite apparent, as three regions of positive temperature departures are shown to be centered at longitude $70^{\circ}, 180^{\circ}$, and $300^{\circ}$, respectively.

[17] Downward phase progression is also clearly observed in the MLS temperature profiles. Figure $3 \mathrm{a}$ is the timeheight section of the cosine coefficients for the projection of the temperature anomalies onto the zonal wave number 3 . Although only a broad band-pass filter for wave periods between 3 and 45 days is applied in this plot, a coherent downward progression structure is clearly exhibited in the vertical range between 6 and $60 \mathrm{hPa}$. Its time period is about 8 days. The corresponding sine coefficients (not shown here) show a similar structure but lag a nearly quarter cycle behind the cosine ones. Moreover, the periodic structure and downward phase propagation also appear in the MLS ozone data (Figure $3 b$ ), but with large variations being confined to a small vertical range between 10 and $40 \mathrm{hPa}$.

\subsection{Mode Identification}

[18] To identify Kelvin modes in the temperature anomalies associated with zonal wave 3, an extended empirical orthogonal function analysis is made on the cosine coefficients shown in Figure 3a. The same technique was used by Mote et al. [2002] in deriving Kelvin wave signatures from UARS MLS temperature data. Here, we use a time window of \pm 15 days to find wave patterns at the vertical range between 0.1 and $215 \mathrm{hPa}$. Our results are not sensitive to the choice of the time window nor to the top and bottom pressures. Generally, the extended EOFs for a propagating wave are found as conjugate pairs characterized by nearly equal eigenvalues and similar structure with one quarter cycle time shift between each other [Mote et al., 2002]. The first two extended EOFs for the wave 3 component (cosine) of the MLS temperature anomalies are hence combined and displayed in Figure 4a against lag time and pressure. This extended EOF pair represent more than $26 \%$ of the total variance contained by the wave 3 component. In the vertical range $6-70 \mathrm{hPa}$, Figure $4 \mathrm{a}$ exhibits a coherent vertical structure corresponding to a downward phase propagation at a period of about 8 days. In other words, this wave mode has a zonal phase speed around $19 \mathrm{~m} / \mathrm{s}$. In Figure $4 \mathrm{~b}$, the principal components (PCs) for the first and second extended EOFs are depicted as a function of the days since 15 August 2005. Clearly, the first two extended PCs are in good quadrature relation, which is further evidence for the propagating wave represented by the extended EOF pair shown in Figure 4a. Note that similar results are also obtained when the same analysis is repeated for the sine coefficients.

[19] Close examination of the wave structure in Figure 4a reveals that the vertical wavelength is about $11 \mathrm{~km}$, com-
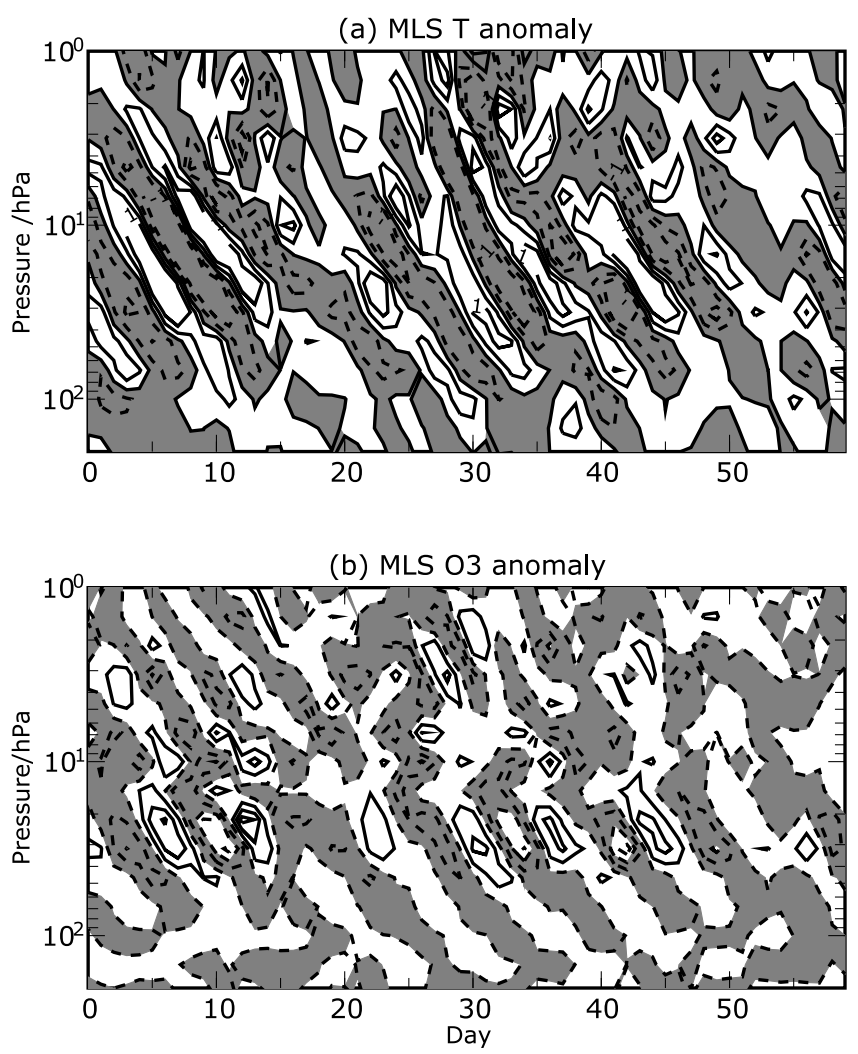

Figure 3. (a) Time-pressure (height) section for wave 3 component (cosine) of the MLS temperature anomalies. Here, the contour interval is $1.0 \mathrm{~K}$ with negative values shaded. (b) Same as Figure 3a but for ozone anomalies, with contour interval chosen to be 0.05 ppmv. 


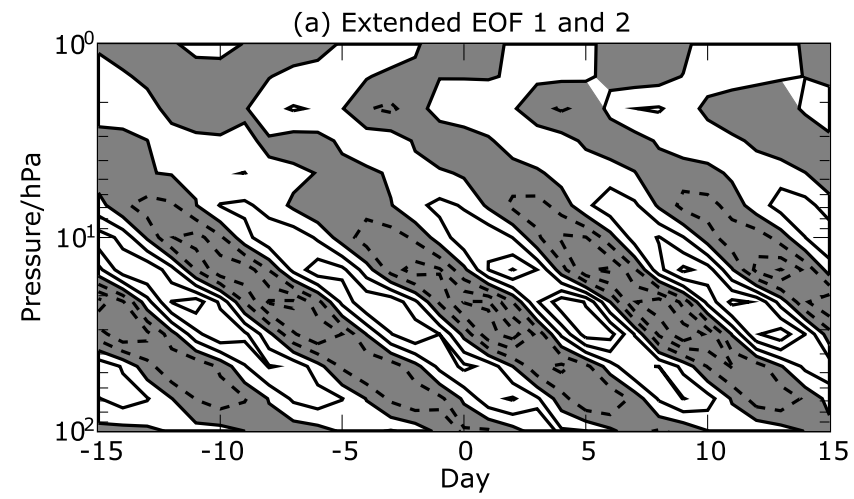

(b) Extended PC 1 and 2

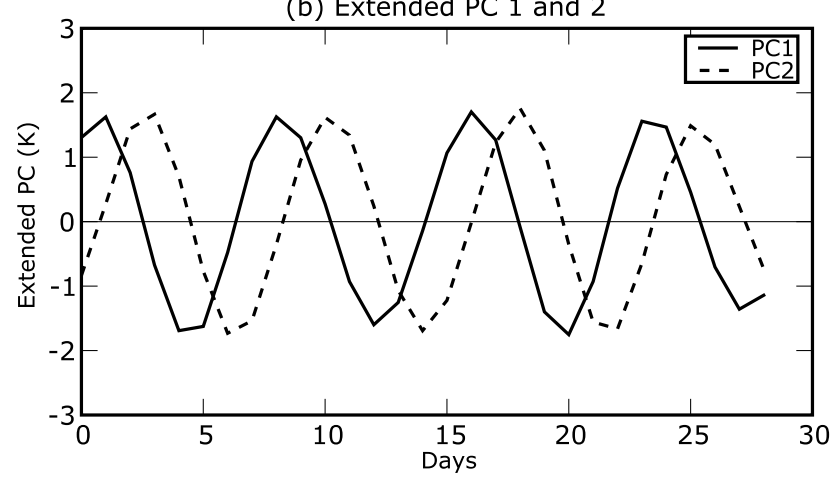

Figure 4. (a) Lag time-pressure diagram of the first and second extended EOFs of the wave 3 component (cosine) detected in the MLS temperature anomalies. (b) First (solid line) and second (dashed line) extended principal components (PC) as a function of days since 15 August 2005.

pared to a value of $12 \mathrm{~km}$ calculated from the Kelvin wave dispersion equation [Salby and Garcia, 1987; Timmermans et al., 2005b]:

$$
c-\bar{u} \approx-\frac{N}{m},
$$

with the phase speed $c$ given by

$$
c=\omega / k
$$

[20] In the above equations, $\omega$ is the wave frequency, $k$ is the zonal wave number, $m$ denotes the vertical wave number and $\bar{u}$ is the mean zonal wind. The latter is obtained by averaging the wind analyses from the ozone assimilation experiment between $10^{\circ} \mathrm{S}$ and $10^{\circ} \mathrm{N}$ for the 60 -day time period, and shown in Figure 5a. Also, the Brunt-Väisälä frequency $N$ is defined by

$$
N^{2}=g\left(\frac{1}{\bar{T}} \frac{\partial \bar{T}}{\partial z}+\frac{1}{H} \frac{R}{c_{p}}\right),
$$

where $\bar{T}$ denotes the zonal mean MLS temperature profile shown in Figure 5b, $z$ is the vertical coordinate (height), $H$ is the scale height $(\sim 7.3 \mathrm{~km}), c_{p}$ is the specific heat for constant pressure, and $R$ and $g$ denote the gas constant for dry air and gravity constant, respectively.
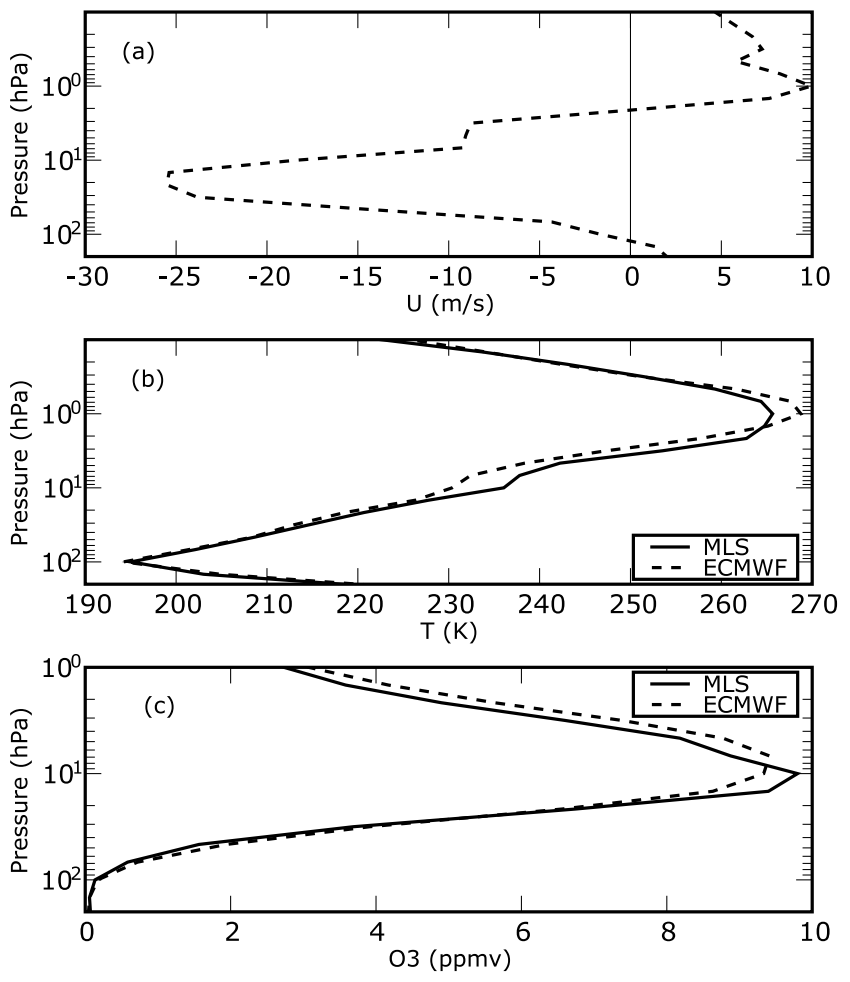

Figure 5. Time and zonal-averaged profiles for (a) the ECMWF zonal wind, (b) the MLS (solid line) and ECMWF (dashed line) temperature, and (c) the MLS (solid line) and ECMWF (dashed line) ozone, respectively.

[21] In the upper stratosphere, Figure 4a shows a rather chaotic pattern, although the regular patterns in the lower and middle stratosphere apparently represent a propagating wave with vertical wavelength and phase speed satisfying the dispersion relation for Kelvin waves. When damping is ignored, the power of a Kelvin wave in a homogeneous atmosphere is expected to increase exponentially with altitude, while being meridionally confined around the equator [Salby and Garcia, 1987]. The equatorial trapping of the observed eastward zonal wave 3 can be verified in Figure 6, where the total wave power for periods 5-10 days is displayed in the latitude-pressure section. Here, the FT

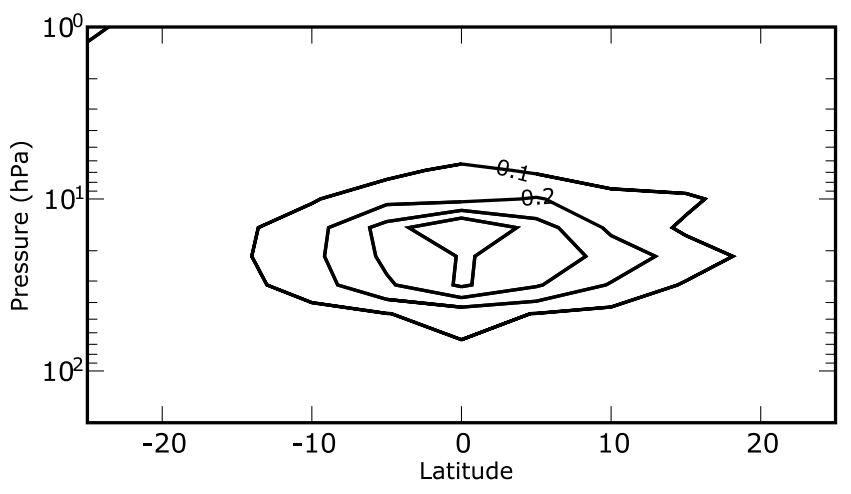

Figure 6. Longitude-pressure section for the wave power of the temperature anomalies, calculated for zonal wave 3 with periods between 5 and 10 days, with contour interval equal to $0.1 \mathrm{~K}^{2}$. 


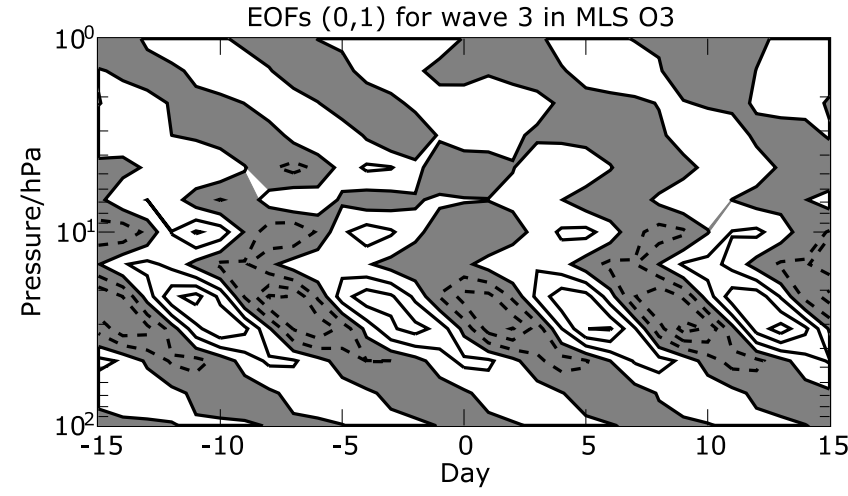

Figure 7. Same as Figure 4a but for the MLS ozone perturbations.

analysis is made on the MLS temperature data binned into latitude-longitude grids with width of $5^{\circ}$ latitude and $24^{\circ}$ longitude. However, the vertical distribution of the wave power is rather complicated: the wave power rapidly increases with altitude, and peaks around $15 \mathrm{hPa}$ before decreasing at a steep rate for higher altitudes.

[22] When a strong westerly vertical wind sheer exists, rapid dissipation of wave power is expected near the critical level where $c=\bar{u}$ [Salby and Garcia, 1987]. The ECMWF wind analyses (Figure 5a) suggest that the mean zonal wind changes from easterly (with maximal speed $-25 \mathrm{~m} / \mathrm{s}$ at $20 \mathrm{hPa}$ ) to westerly around $2 \mathrm{hPa}$, where a dissipation layer could be formed to prevent slow Kelvin waves propagating into the upper stratosphere. However, the observed MLS wave power peaks at a much lower altitude $(10-20 \mathrm{hPa})$, implying that the main cause for its energy loss is thermal damping [Hitchman and Leovy, 1988; Randel and Wu, 2005].

\subsection{Ozone Variations Induced by Kelvin Waves}

[23] The same extended EOF analysis is repeated for the MLS ozone observations, and the resulting first and second extended EOFs are displayed in Figure 7. It is noted that the structure below $10 \mathrm{hPa}$ corresponds to a downward propagation at a period of about 8 days, consistent with the temperature anomalies shown in Figure 4a. However, large ozone perturbations are found to be mainly confined between 15 and $40 \mathrm{hPa}$, and a disruption to the vertical phase propagation occurs around $10 \mathrm{hPa}$.

[24] The features seen in Figure 7 can be understood in the framework of linear theory [Salby et al., 1990], which predicts that when chemical sink/generation can be ignored, perturbations in the ozone volume mixing ratio $\chi^{\prime}$ are related to the temperature anomaly $T^{\prime}$ via

$$
\chi^{\prime}=\frac{g}{N^{2}} \frac{T^{\prime}}{\bar{T}} \frac{\partial \bar{\chi}}{\partial z}
$$

where $\bar{\chi}$ denotes the averaged ozone profiles. Equation (3) implies that when ozone fluctuation is mainly caused by vertical displacement of air parcels, and $T^{\prime}$ has slowly varying amplitude with height, its (ozone's) largest amplitude would appear at the altitude where the mean ozone profile has its steepest vertical gradient. Figure 5c compares the mean ozone profiles from MLS observations with the ECMWF analyses, showing that the ozone mixing ratio increases with height, and reaches its peak around
$10 \mathrm{hPa}$ before decreasing gradually. The mean MLS ozone profile has largest vertical gradient around $20-30 \mathrm{hPa}$, where largest ozone perturbations are seen in both Figures 6 and $3 \mathrm{~b}$, consistent with equation (3).

[25] Figure 8a directly compares the wave 3 component (cosine coefficient) of the observed ozone perturbations at $21.5 \mathrm{hPa}$ with that derived from the temperature anomalies using equation (3). It is noted that the ozone fluctuations (the dashed line) are in phase with the temperature perturbations (the dotted line). Moreover, the inferred ozone variation (the solid line) is indeed in good agreement with the observations (but with a slightly overestimated oscillation amplitude). Since in equation (3), only transport effects are taken into account, the good agreement suggests that the vertical displacement of air parcels dominates the cause of the large-scale ozone perturbations observed in the lower tropical stratosphere.

[26] At higher altitudes (Figure 8b), the ozone perturbations become out phase with the temperature wave, and moreover, the ozone variation inferred from the temperature perturbations accounts for only a small part of the observed oscillations. This result reflects the importance of chemical processes in this vertical range [Randel and Gille, 1991].

\section{Eastward Tropical Waves Revealed by EOS MLS Observations and ECMWF Analyses}

[27] Figure 9 presents the power spectra for the eastward traveling temperature anomalies detected in the MLS data
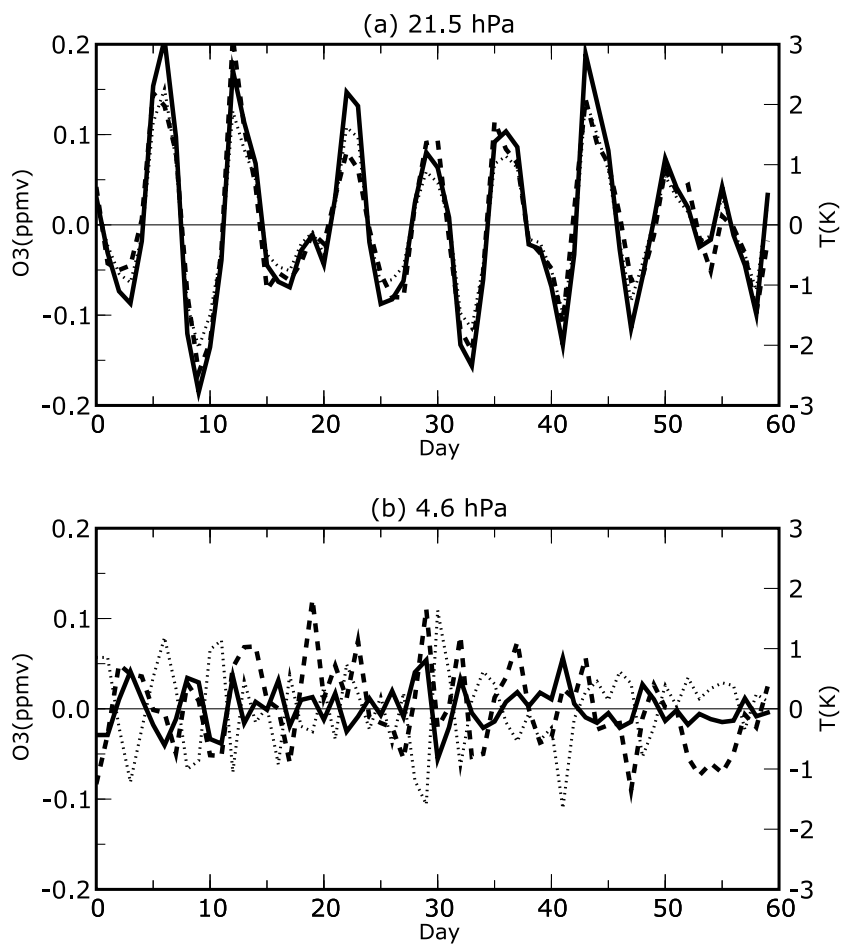

Figure 8. Wave 3 components (cosine) of the MLS ozone anomalies (dashed lines) compared with the ones inferred from the MLS temperature variations using equation (3) (solid lines) at (a) $21.5 \mathrm{hPa}$ and (b) $4.6 \mathrm{hPa}$, respectively. For comparison, the wave 3 components of the MLS temperature anomalies are also presented as dotted lines. 
(a) $k=1$

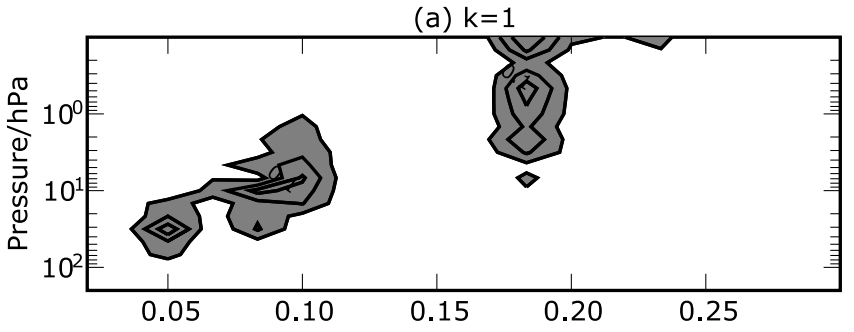

(b) $k=2$

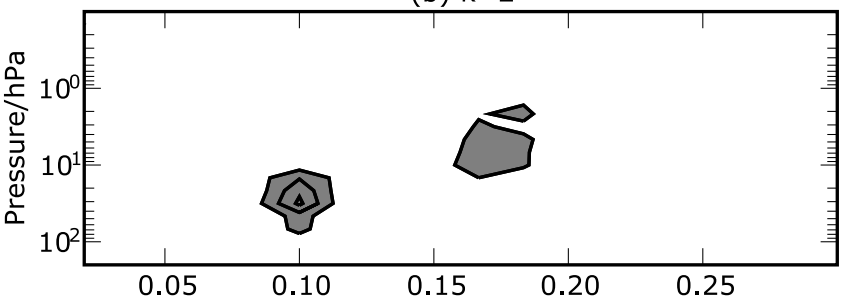

(c) $k=3$

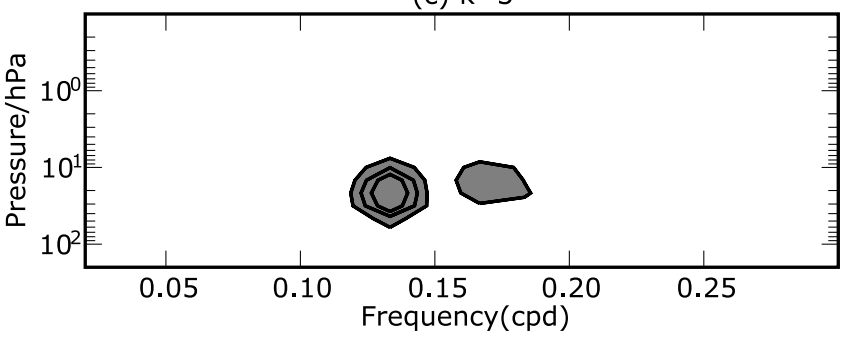

Figure 9. Power spectra calculated for the eastward MLS temperature anomalies with zonal wave number $k=1$ to 3 , respectively. Here, the contour interval is $0.05 \mathrm{~K}^{2}$, and the values larger than $0.05 \mathrm{~K}^{2}$ are shaded.

set during the autumn of 2005. Here, the wave powers for zonal wave number $k=1$ to 3 are calculated at each MLS pressure level and displayed in Figures 9a-9c, respectively. For frequencies larger than 0.20 cycles per day (cpd) (i.e., wave periods shorter than 5 days), no strong power concentration is found in the stratosphere for zonal waves $1-3$. However, around $0.18 \mathrm{cpd}$, zonal wave 1 (Figure 9a) exhibits a strong power concentration in the vertical range $0.1-3 \mathrm{hPa}$. Meanwhile, weaker disturbances of zonal wave 2 and 3 are found at slightly smaller frequencies. Note that the disturbances of zonal wave 2 and 3 are trapped below $2 \mathrm{hPa}$, reflecting heavier damping for slower waves [Salby and Garcia, 1987] as well as possible dissipation due to the vertical wind shear in the upper stratosphere (see Figure 5a).

[28] At the lower frequencies, several power peaks are found in the lower stratosphere, and the strongest one appears in zonal wave 3 around $0.13 \mathrm{cpd}$ (period $7-8$ days), which just corresponds to the Kelvin wave mode identified in the previous section. Most previous studies suggest that in the middle and lower stratosphere, zonal wave 1 and 2 account for most of the observed large-scale temperature variations [e.g., Mote et al., 2002; Randel and Wu, 2005], while weak signatures for high zonal wave numbers $(>2)$ could be attributed to some highly localized perturbations [Shiotani et al., 1997]. In fact, as shown in Figure 1, MLS temperature and ozone observations also confirm the dominance of zonal wave 1 and 2 at time periods other than the autumn of 2005. The unusual surge of zonal wave 3 is believed to be related to the characteristics of the relevant excitation, and in particular, to the wind conditions in the autumn of 2005. The theoretical simulations by Holton [1973] and Salby and Garcia [1987] suggest that the wave packets generated by deep convection usually consist of different modes, and the most favored mode can be shifted to high zonal wave numbers if the heating source has a quite short timescale. In fact, tropospheric Kelvin waves of high zonal wave numbers $(>2)$ have been revealed in several observations [Wheeler and Kiladis, 1999]. On the other hand, for a given wave frequency, a higher zonal wave number means a lower phase speed, and hence a smaller (westerly) wind speed required to form a dissipation layer to prevent its further upward propagation. So, the strong easterly wind shown in the tropical lower stratosphere during the autumn of 2005 (see Figure 5a) provides a necessary condition for the propagation of slow Kelvin waves.

[29] As mentioned before, the temperature analyses (referred to as the ECMWF analyses) from the experimental assimilation of MLS ozone are mainly bound by direct assimilation of radiances from nadir instruments, and are essentially independent of MLS temperature data. However, in the lower stratosphere, the wave 3 components of the temperature anomalies in the ECMWF analyses also show a strong power concentration around $0.13 \mathrm{cpd}$ (Figure 10c), consistent with the slow Kelvin wave of zonal wave number 3 revealed in MLS data. More generally, Figure 10 shows that for zonal wave 1 to 3 , the frequencies of the power peaks found in the ECMWF temperature analyses coincide

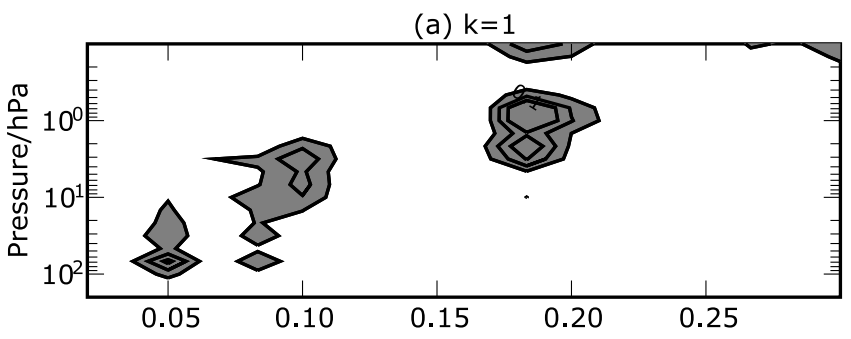

(b) $k=2$

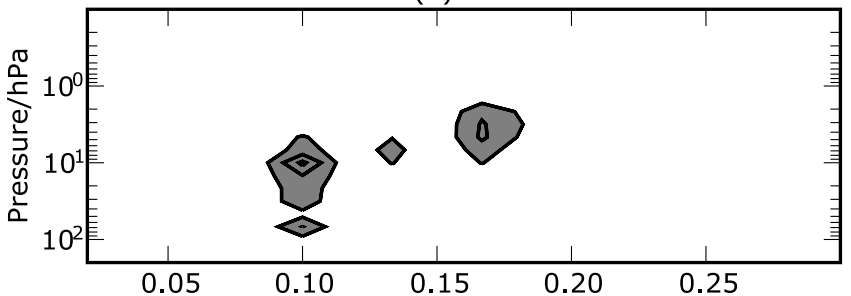

(c) $k=3$

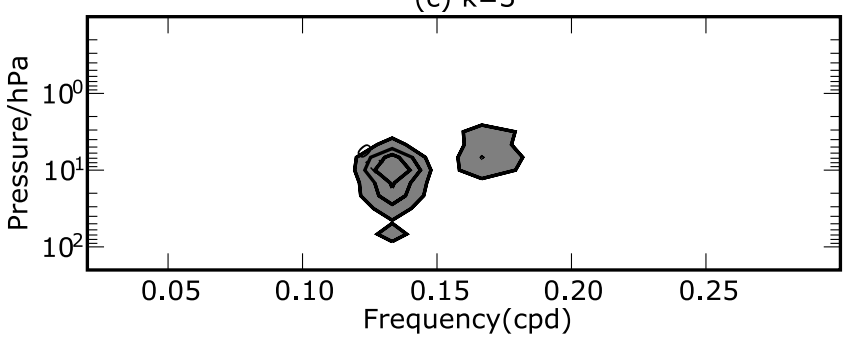

Figure 10. Same as Figure 9 but for ECMWF temperature analyses. 

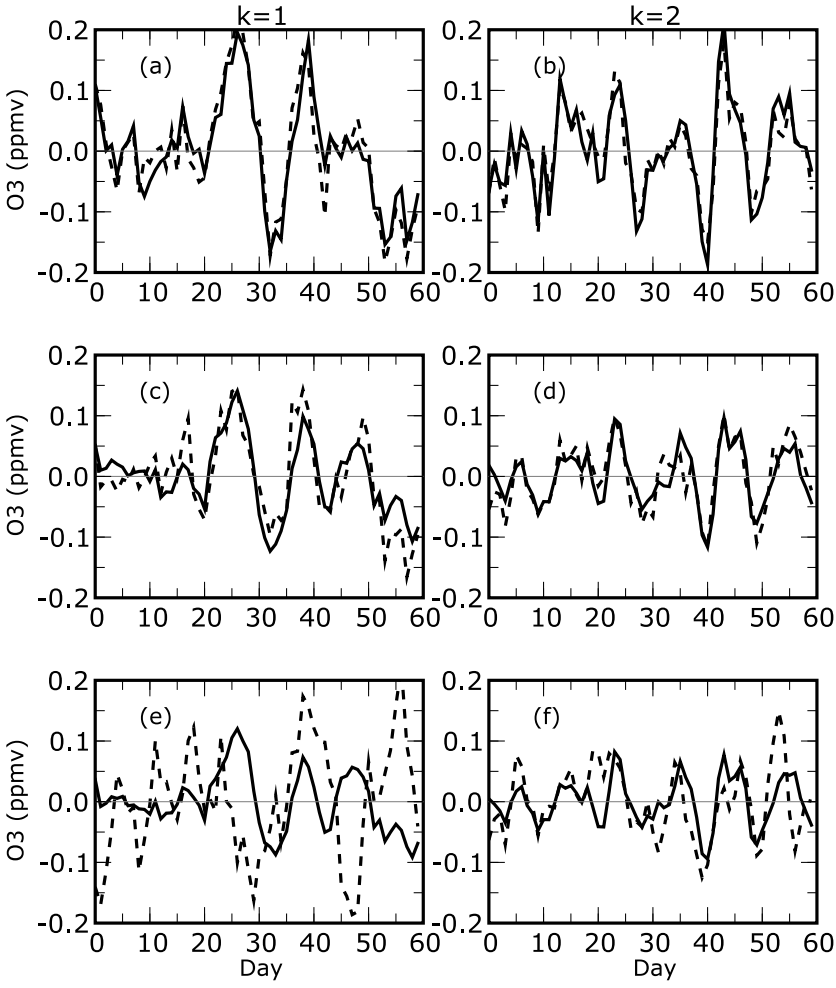

Figure 11. ( $a$ and $b$ ) Wave 1 and 2 components (cosine) of the MLS ozone anomalies (dashed lines) at $21.5 \mathrm{hPa}$ compared with the ones inferred from the MLS temperature perturbations (solid lines), respectively. (c and d) Same as Figures $11 \mathrm{a}$ and $11 \mathrm{~b}$ but for the ECMWF ozone and temperature analyses. (e and f) Results for the control run where no MLS ozone profile is assimilated into the ECMWF data assimilation system.

very well with MLS data. On the other hand, their vertical positions in the middle and lower stratosphere are usually shifted toward higher altitudes. Such vertical shifts may partly be attributed to the poor vertical resolution of the operational temperature (radiance) observations assimilated in the experiment, as well as the limited vertical resolution (4-6 km) of the current MLS temperature retrievals.

[30] Similar FT analysis also reveals several power concentrations from MLS ozone observation (not shown here). These power concentrations peak almost at the same pressure (height) level, where the mean ozone profile shows the largest vertical gradient. More importantly, as shown in Figures $11 \mathrm{a}$ and $11 \mathrm{~b}$, just like the zonal wave 3 , the observed ozone fluctuations of zonal wave 1 and 2 are also in good agreement with those derived from the MLS temperature anomalies using equation (3), highlighting the contribution of the wave-driven vertical displacement of air parcels to the observed large-scale ozone fluctuations in the tropical lower stratosphere. Similar results are presented in Figures $11 \mathrm{c}$ and $11 \mathrm{~d}$ for the ECMWF temperature and ozone analyses after assimilating MLS ozone profiles. Interestingly, although the ECMWF ozone analyses at $21.5 \mathrm{hPa}$ show smaller fluctuation amplitudes for zonal wave $1-2$, their variations are coincident with the temperature waves detected in the temperature analyses. For comparison, Figures $11 \mathrm{e}$ and $11 \mathrm{f}$ present the results for the control run in which only the operational ozone observations from nadir instruments (SBUV/2 and SCIAMACHY) are assimilated. Obviously, without effective constraints on the lower stratospheric ozone, fluctuations detected in the ozone analyses are very poorly correlated with the temperature perturbations, reflecting the problems in modeling the tropical tracer transport [Schoeberl et al., 2003].

[31] When the extended EOF analysis is applied to the temperature anomalies of zonal wave number 1 to 3 , several Kelvin modes are identified. As one example, Figures $12 a-12 c$ present the first two extended EOFs extracted from the zonal wave 1 to 3 components (cosine) of the ECMWF temperature analyses. Note that the pattern shown in Figure 12c corresponds to a Kelvin wave of zonal wave number 3 , and is essentially the same as that derived from the MLS temperature data (see Figure 4a). The pattern seen in Figure $12 \mathrm{~b}$ represents one slow Kelvin wave of zonal wave number 2 , which propagates in the middle and lower stratosphere at a phase speed of $23 \mathrm{~m} / \mathrm{s}$ and a period of about 10 days. Its vertical wavelength is estimated to be $13 \mathrm{~km}$, compared to a value of $12 \mathrm{~km}$ from the dispersion equation. The same mode is also identified in the MLS observations but from the pattern represented by the extended EOFs 3 and 4 (not shown here).

[32] Figure 12a shows a clear periodic downward (phase) propagation at the pressure range between 0.3 and $5 \mathrm{hPa}$. This regular wave-like pattern corresponds to the strong

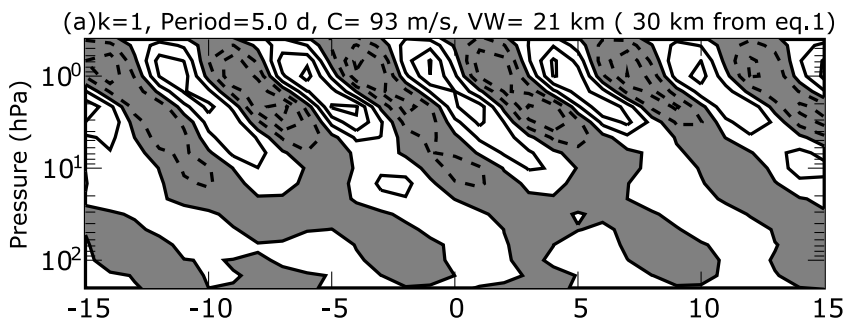

(b) $k=2$, Period $=10.0 \mathrm{~d}, \mathrm{C}=23 \mathrm{~m} / \mathrm{s}, \mathrm{VW}=13 \mathrm{~km}$ ( $14 \mathrm{~km}$ from eq. 1 )

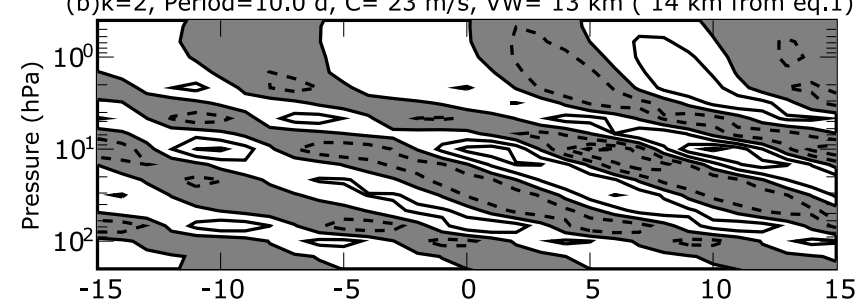

(c)k=3, Period =8.0 d, C= $19 \mathrm{~m} / \mathrm{s}, \mathrm{VW}=12 \mathrm{~km}$ ( $12 \mathrm{~km}$ from eq.1)

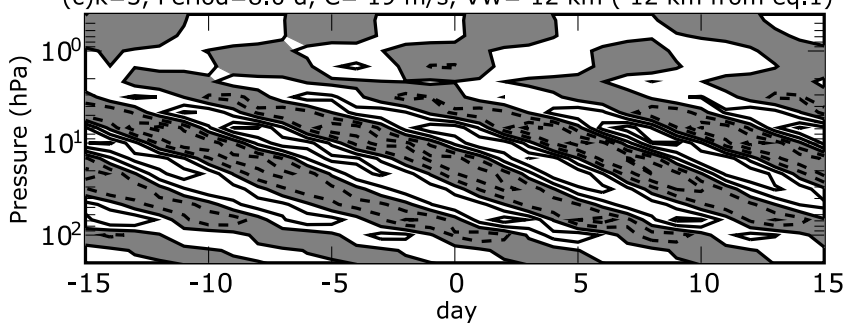

Figure 12. Lag time-pressure diagram for the first and second extended EOFs of the wave 1-3 components (cosine) detected in the ECMWF temperature anomalies. Here, the period, phase speed (referred to as C) and the estimated vertical wavelengths (referred to as VW) are given in the title of each subplot. 
power concentration seen around the frequencies $0.16-$ $0.2 \mathrm{cpd}$ in Figure 10a. It possibly represents a fast Kelvin mode of period $\sim 5$ days and phase speed about $93 \mathrm{~m} / \mathrm{s}$. While it has many Kelvin wave features, such as the trapped power distribution in the meridional direction, the vertical wavelength estimated from Figure $12 \mathrm{a}$ is about $21 \mathrm{~km}$ (24 km for MLS data), quite different from $30 \mathrm{~km}$ given by the dispersion equation. However, estimation of the wind speed at the top of stratosphere is problematic, because of the strong vertical wind shear as well as the large uncertainty in the ECMWF wind analyses. As a result, large errors may occur in the wavelength estimated from the dispersion relation due to the unreliable wind speed.

\section{Summary}

[33] We have used FT and extended EOF analysis to identify Kelvin modes from the EOS MLS temperature and ozone observations during the autumn of 2005. A Kelvin wave mode with zonal wave number equal to 3 is identified in the middle and lower stratosphere. This mode represents a slow Kelvin wave of phase speed $\sim 19 \mathrm{~m} / \mathrm{s}$ and vertical wavelength $\sim 11 \mathrm{~km}$. It exhibits coherent temperature fluctuations in the vertical range between 6 and $60 \mathrm{hPa}$, with the largest amplitude (up to $2 \mathrm{~K}$ ) seen around $20 \mathrm{hPa}$. It also induces fluctuations in the tropical stratospheric ozone, which may reach $0.2 \mathrm{ppmv}$ at the altitude with the largest vertical gradient of the mean ozone profile. Moreover, in the lower stratosphere, the observed ozone fluctuations exhibit a clear in-phase relation with the temperature anomalies, as expected by linear theory for the ozone variations caused by the wave-driven vertical displacement of air parcels. However, in the other time periods, EOS MLS observations suggest that zonal wave 1 and 2 dominate the wave activity detected in the middle and lower tropical stratosphere, consistent with previous satellite-borne observations. The wind condition during the autumn of 2005 allows the propagation of slow Kelvin waves in the tropical middle and lower stratosphere. However, the excitation of a strong Kelvin wave of zonal wave 3 in the absence of stronger signatures for zonal wave 1 or 2 is of great interest, and deserves further investigation.

[34] The same Kelvin mode of zonal wave number 3 is also found in the experimental ECMWF analyses where ozone profiles from EOS MLS are assimilated along with other operational observations. Our study shows that the Kelvin wave activity described by the ECMWF temperature analysis is in good agreement with EOS MLS observations. In particular, after assimilating the vertically resolved ozone data from EOS MLS, the large-scale fluctuations in the analyzed tropical stratospheric ozone field become more consistent with the temperature perturbations, and can be used to derive useful information on the equatorial Kelvin waves. However, compared to MLS temperature observations, the wave power concentrations detected in the ECMWF temperature analyses are generally shifted toward higher altitudes. Such vertical shifts may partially be caused by the poor vertical resolution of the operational temperature observations. At the meantime, the possible relation of this discrepancy with deficiencies in modeling wave excitation and dissipation will be further explored in the future study using the improved MLS retrievals of version 2.2.
[35] Acknowledgments. The authors would like to thank D. Wu and M. Hitchman for their helpful comments. We wish to acknowledge technical and scientific support from the ECMWF for us to use their data assimilation system and are particularly grateful for kind help from E. V. Hólm and A. Dethof. The authors also thank the referees for their suggestions in helping improve this paper. This study is funded by the U.K. Natural Environment Research Council through the Data Assimilation Research Centre. Work at the Jet Propulsion Laboratory, California Institute of Technology, was carried out under a contract with NASA.

\section{References}

Amodei, M., S. Pawson, A. A. Scaife, U. Langematz, W. Lahoz, D. M. Li, and P. Simon (2001), The SAO and Kelvin waves in the EuroGRIPS GCMS and the UK Met Office analyses, Ann. Geophys., 19, 99-114.

Bhartia, P. K., R. D. McPeters, C. L. Mateer, L. E. Flynn, and C. Wellemeyer (1996), Algorithm for the estimation of vertical ozone profiles from the backscattered ultraviolet technique, J. Geophys. Res., 101, 18,79318,806 .

Boehm, M. T., and J. Verlinde (2000), Stratospheric influence on upper tropospheric tropical cirrus, Geophys. Res. Lett., 27, 3209-3212.

Canziani, P. O., and J. R. Holton (1998), Kelvin waves and the quasibiennial oscillation: An observational analysis, J. Geophys. Res., 103, 31,509-31,522.

Dethof, A. (2003), Assimilation of ozone retrievals from the MIPAS instrument on board ENVISAT, Tech. Memo. 428, Eur. Cent. for Med.-Range Weather Forecasts, Bracknell, U. K.

Dethof, A., and E. V. Hólm (2004), Ozone assimilation in the ERA-40 reanalysis project, Q. J. R. Meteorol. Soc., 130, 2851-2872.

Elson, L., and L. Froidevaux (1993), The use of Fourier transforms for asynoptic mapping: Application to the Upper Atmosphere Research Satellite Microwave Limb Sounder, J. Geophys. Res., 98, 23,039-23,050.

Eskes, H. J., R. J. van der A, E. J. Brinksma, J. P. Veefind, J. F. De Haan, and P. J. M. Valks (2005), Retrieval and validation of ozone columns derived from measurement of SCIAMACHY on Envisat, Atmos. Chem. Phys. Discuss., 5, 4429-4475.

Froidevaux, L., et al. (2006), Early validation analyses of atmospheric profiles from EOS MLS on the Aura satellite, IEEE Trans. Geosci. Remote Sens., 44, 1106-1121.

Fujiwara, M., and M. Takahashi (2001), Role of the equatorial Kelvin wave in stratosphere-troposphere exchange in a general circulation model, J. Geophys. Res., 106, 22,763-22,780

Hitchman, M. H., and C. B. Leovy (1988), Estimation of the Kelvin wave contribution to the semiannual oscillation, J. Atmos. Sci., 45, 1462-1475.

Holton, J. R. (1973), On the frequency distribution of atmospheric Kelvin waves, J. Atmos. Sci., 30, 499-501.

Mote, P. W., and T. J. Dunkerton (2004), Kelvin wave signatures in stratospheric trace constituents, J. Geophys. Res., 109, D03101, doi:10.1029/ 2002JD003370.

Mote, P. W., T. J. Dunkerton, and D. Wu (2002), Kelvin waves in stratospheric temperature observed by the Microwave Limb Sounder, J. Geophys. Res., 107(D14), 4218, doi:10.1029/2001JD001056.

Randel, W. J. (1990), Kelvin-wave induced constituent oscillations in the equatorial stratosphere, J. Geophys. Res., 95, 18,641-18,652.

Randel, W. J., and J. C. Gille (1991), Kelvin wave variability in the upper stratosphere observed in SBUV ozone data, J. Atmos. Sci., 48, 2330-2349.

Randel, W. J., and F. Wu (2005), Kelvin wave variability near the equatorial tropopause observed in GPS radio occultation measurements, J. Geophys. Res., 110, D03102, doi:10.1029/2004JD005006.

Salby, M. L. (1982), Sampling theory for asynoptic satellite observations, part I: Space-time spectra, resolution and aliasing, J. Atmos. Sci., 39, $2577-2600$

Salby, M. L., and R. R. Garcia (1987), Transient response to localized episodic heating in the tropics. Part I: Excitation and short-term near-field behavior, J. Atmos. Sci., 44, 458-498.

Salby, M. L., D. L. Hartmann, P. L. Bailey, and J. C. Gille (1984), Evidence for equatorial Kelvin modes in Nimbus-7 LIMS, J. Atmos. Sci., 41, $220-$ 235.

Salby, M. L., P. Callaghan, S. Solomon, and R. Garcia (1990), Chemical fluctuations associated with vertically propagating equatorial Kelvin waves, J. Geophys. Res., 95, 20,491-20,505.

Schoeberl, M. R., A. R. Douglass, Z. Zhu, and S. Pawson (2003), A comparison of the lower stratospheric age spectra derived from a general circulation model and two data assimilation systems, J. Geophys. Res., 108(D3), 4113, doi:10.1029/2002JD002652.

Shimizu, A., and T. Tsuda (1997), Characteristics of Kelvin waves and gravity waves observed with radiosondes over Indonesia, J. Geophys. Res., 102, 26,159-26,172.

Shiotani, M., J. C. Gille, and A. E. Roche (1997), Kelvin waves in the equatorial lower stratosphere as revealed by cryogenic limb array etalon spectrometer temperature data, J. Geophys. Res., 102, 26,131-26,140. 
Straub, K. H., and G. N. Kiladis (2002), Observation of a convectively coupled Kelvin wave in the eastern Pacific ITCZ, J. Atmos. Sci., 59 $30-53$.

Swinbank, R., and A. O'Neill (1994), A stratosphere-troposphere data assimilation system, Mon. Weather Rev., 122, 686-702.

Timmermans, R. M. A., R. F. van Oss, and H. M. Kelder (2005a), Equatorial Kelvin wave signatures in ozone profile measurements from Globa Ozone Monitoring Experiment (GOME), J. Geophys. Res., 110, D21103, doi:10.1029/2005JD005929.

Timmermans, R. M. A., R. F. van Oss, and H. M. Kelder (2005b), Kelvin wave signatures in ECMWF meteo fields and Global Ozone Monitoring Experiment (GOME) ozone columns, J. Geophys. Res., 110, D13104, doi:10.1029/2004JD005261

Tindall, J. C., J. Thuburn, and E. J. Highwood (2006), Equatorial waves in the lower stratosphere. I: A novel detection method, Q. J. R. Meteorol. Soc., 132, 177-194.
Waters, J., et al. (2006), The Earth Observation System Microwave Limb Sounder (EOS MLS) on the Aura satellite, IEEE Trans. Geosci. Remote Sens., 44, 1075-1092.

Wheeler, M., and G. N. Kiladis (1999), Convectively coupled equatorial waves: Analysis of clouds and temperature in the wavenumber-frequency domain, J. Atmos. Sci., 56, 374-399.

R. Brugge and A. O'Neill, Data Assimilation Research Centre, University of Reading, Reading RG6 6BB, UK

L. Feng and R. S. Harwood, Institute of Atmospheric and Environmental Science, University of Edinburgh, Crew Building, King's Buildings, Edinburgh EH9 3JN, UK.

L. Froidevaux, M. Schwartz, and J. W. Waters, Jet Propulsion Laboratory, California Institute of Technology, Pasadena, CA 91109, USA. 